\title{
Optimalisasi Prediksi Biaya Komisi Penjualan Mobil Menggunakan Metode Monte Carlo
}

\author{
Zupri Henra Hartomi ${ }^{1}$, Yuhandri ${ }^{2}$, Julius Santony ${ }^{3}$ \\ ${ }^{1}$ Program Studi Sistem Informasi, STMIK Hang Tuah Pekanbaru \\ ${ }^{23}$ Magister Ilmu Komputer, Universitas Putra Indonesia YPTK Padang \\ zupri.henra@gmail.com
}

\begin{abstract}
Abstrak
Penjualan merupakan sumber pendapatan utama setiap perusahaan. Setiap perusahaan dalam memasarkan suatu produk, hendaknya menguasai pasar yang potensial untuk mendapatkan keuntungan. Memprediksi jumlah penjualan merupakan hal penting dalam menganalisis perkembangan penjualan. Penelitian ini bertujuan untuk membantu perusahaan dalam memprediksi penjualan mobil dan anggaran biaya komisi mobil berdasarkan data penjualan dari tahun sebelumnya. Data yang digunakan dalam penelitian adalah data penjualan mobil Tahun 2017 dan Tahun 2018 di Showroom Arengka Automall Pekanbaru (SAA Pekanbaru). Pengolahan data dalam penelitian ini menggunakan metode Monte Carlo. Hasil dari pengujian yang telah dilakukan menyatakan bahwa penjualan mobil oleh Marketing dalam kurun waktu 1 tahun menghasilkan rata-rata tingkat akurasinya sebesar 94\% dan biaya komisi penjualan sebesar Rp 411.000.000. Dari hasil tersebut sesuai dengan perhitungan yang dilakukan secara manual sehingga dengan nilai akurasi yang besar tersebut, maka penerapan simulasi menggunakan Metode Monte Carlo ini layak untuk diterapkan oleh perusahaan dalam pengambilan keputusan dimasa yang akan datang untuk merencanakan estimasi anggaran biaya komisi penjualan mobil dan sebagai salah satu sarana untuk menilai kinerja Marketing di SAA Pekanbaru.
\end{abstract}

Kata kunci: Prediksi; Penjualan; Monte Carlo; Pemodelan; Simulasi.

\begin{abstract}
Sales are the main source of income for every company. Every company in marketing a product, should control the potential market for profit. Predicting the number of sales is important in analyzing sales progress. This study aims to assist companies in predicting car sales and car commission cost budgets based on sales data from the previous year.The data used in the study are car sales data for 2017 and 2018 in the Arengka Automall Pekanbaru Showroom (SAA Pekanbaru).Data processing in research uses the Monte Carlo method.The results of tests that have been carried out state that car sales by Marketing within 1 year resulted in an average accuracy rate of $94 \%$ and sales commission fee of Rp 411.000.000.From these results in accordance with calculations performed manually so that with a large accuracy value, the application of the simulation using this Monte Carlo Method feasible to be applied by companies in future decision making to plan the estimated budget for the cost of a car sales commission and as a means to assess Marketing performance at SAA Pekanbaru.
\end{abstract}

Keywords: Prediction; Sales; Monte Carlo; Modeling; Simulation.

\section{Pendahuluan}

Suatu perusahaan agar dapat berkembang dan bertahan diperlukan pengelolaan manajemen usaha yang baik dan selalu melakukan Inovasi untuk mengantisipasi persaingan dengan produkproduk kompetitor lain yang semakin memenuhi pasar [1]. Showroom Arengka Automall (SAA) Pekanbaru adalah perusahaan terkemuka yang bergerak di bidang sales mobil yang melayani penjualan mobil baru, bekas dan tukar tambah dengan sistem pembayaran cash dan kredit. 
Seiring dengan pertumbuhan Kota Pekanbaru yang begitu pesat di mana kebutuhan masyarakat terhadap kepemilikan kendaraan begitu tinggi ditandai dengan peningkatan penjualan mobil setiap tahunnya, namun dengan tingginya penjualan mobil di SAA Pekanbaru tidak diiringi oleh sistem persediaan mobil karena saat ini masih menggunakan intuisi dan kebiasaan serta sistem order atau pesanan dari konsumen. Kesalahan dalam penaksiran persediaan menjadi sangat beresiko ketika menggunakan model yang masih sederhana tersebut [2]. SAA Pekanbaru mengembangkan usahanya berorientasi pada permintaan pasar agar dapat mengukur kinerja bagian pemasarannya [3], Salah satu strategi pemasaran yang dilakukan SAA Pekanbaru adalah menggunakan jasa Marketing dengan target penjualan yang telah ditetapkan dan pemberian biaya komisi atau insentif terhadap setiap unit mobil yang terjual, Perhitungan komisi dengan jumlah tetap adalah perhitungan biaya komisi dengan jumlah yang ditetapkan dan nilai yang ditetapkan tersebut tidak akan berubah [4]. Komisi atau insentif adalah biaya kompensasi yang diberikan tergantung hasil yang dicapai sedangkan penjualan adalah suatu proses pertukaran barang atau jasa antara penjual dan pembeli [5] sehingga komisi penjualan dapat diartikan sebagai biaya kompensasi yang diberikan terhadap hasil dari penjualan barang atau jasa.

Prediksi komisi penjualan mobil adalah salah satu cara yang efektif sebab berkaitan erat dengan peramalan atau proses perkiraan pendapatan dari penjualan mobil dan biaya komisi penjualan yang akan dikeluarkan oleh SAA Pekanbaru, Menghadapi situasi probabilistik seperti ini diperlukan suatu metode untuk menganalisis atau memprediksi kemungkinan kedepannya [6], Sehingga perusahaan dapat mengatasi hilangnya pendapatan akibat kehabisan persediaan dan dapat mencegah pelanggan lari ke kompetitor lain [7] dan merupakan bagian strategi yang tepat dalam peramalan penjualan sebagai dasar untuk perencanaan agar kedepannya perusahaan tidak kehilangan kesempatan dalam menjual produknya []].

Optimalisasi merupakan tahapan untuk menghemat waktu agar lebih efesien [9], sedangkan metode optimasi berbasis simulasi yaitu salah satu alternatif penyelesaian masalah yang dilakukan untuk mendapatkan hasil terbaik [10]. Agar mendapatkan hasil yang terbaik dibutuhkan suatu prediksi yang merupakan proses perkiraan dengan cara membandingkan data histori masa lalu untuk dijadikan pedoman dimasa depan [11]. Teknik melakukan prediksi diperlukan suatu pemodelan yang merupakan proses merancang atau membangun suatu model yang bertujuan untuk mendapatkan informasi baru sebagai alternatif terbaik untuk mendukung pengambilan keputusan dalam penyelesaian masalah. Model simulasi dinilai efektif dalam menyelesaikan permasalahan yang kompleks terutama pada masalah yang sulit diselesaikan dengan model matematis [12]. Pemodelan simulasi diawali dengan memodelkan sistem nyata secara manual, penerapan model tersebut diharapkan menunjukkan bagaimana sejumlah variabel-variabel dalam sistem saling berinteraksi sehingga menggambarkan perilaku sistem, kemudian disimulasikan kedalam progam komputer.

Mensimulasikan berarti mencoba menyesuaikan dengan keadaan sebenarnya secara komputerisasi agar dapat menggambarkan kondisi sistem secara nyata di lapangan [13]. Simulasi Monte Carlo adalah suatu solusi yang dapat menghilangkan ketidakpastian dalam kehandalan pemodelan, karena simulasi Monte Carlo mampu mensimulasi proses nyata dan prilaku dari sistem [14] menggunakan metode penyelesaian masalah yang melibatkan bilangan random dengan distribusi peluang atau kemungkinan yang bisa diketahui dan ditentukan [15]. Proses randomisasi mempunyai distribusi yang berasal dari berbagai variabel data yang dikelompokkan berdasarkan data histori [16], Metode Monte Carlo menggunakan generate probabilitas distribusi bilangan acak yang diolah, kemudian divalidasi dengan data fakta untuk memastikan kondisi simulasi relatif sama kondisi sebenarnya [17]. Monte Carlo merupakan salah satu metode numerik yang dideskripsikan sebagai metode simulasi statis [18] yang dapat diintegrasikan secara numerik oleh prosedur simulasi [19]. Proses probabilitas yang digunakan dalam simulasi Monte Carlo adalah proses distribusi probabilitas kumulatif, yaitu menjumlahkan distribusi probabilitas yang ditambahkan pada probabilitas kumulatif sebelumnya, kecuali untuk nilai distribusi probabilitas untuk kelas pertama, nilai untuk 
distribusi probabilitas komulatif untuk kelas pertama merupakan nilai dari probabilitas kelas itu sendiri [20].

Dari uraian diatas, Simulasi Monte Carlo dapat digunakan untuk memprediksi Biaya Komisi Penjualan Mobil Menggunakan Metode Monte Carlo di Showroom Arengka Automall Pekanbaru

\section{Data dan Metodologi Penelitian}

Data yang digunakan adalah data penjualan mobil Tahun 2017 dan 2018, untuk memperkirakan biaya komisi penjualan mobil yang akan dianggarkan manajemen SAA Pekanbaru di masa akan datang. Data tersebut ditunjukkan pada Tabel 1 dan Tabel 2.

Tabel 1 Rekapitulasi Data Real Penjualan Mobil SAA Pekanbaru Tahun 2017

\begin{tabular}{lccccccccccccc}
\hline \multirow{1}{*}{$\begin{array}{c}\text { Nama } \\
\text { Marketing }\end{array}$} & \multicolumn{10}{c}{ Jumlah Penjualan Setiap Bulan dalam Satuan unit } & & Total \\
\cline { 2 - 17 } & $\mathbf{1}$ & $\mathbf{2}$ & $\mathbf{3}$ & $\mathbf{4}$ & $\mathbf{5}$ & $\mathbf{6}$ & $\mathbf{7}$ & $\mathbf{8}$ & $\mathbf{9}$ & $\mathbf{1 0}$ & $\mathbf{1 1}$ & $\mathbf{1 2}$ & (unit) \\
\hline Ali & 8 & 15 & 11 & 13 & 10 & 10 & 8 & 15 & 17 & 8 & 11 & 12 & 138 \\
\hline Remon & 14 & 13 & 12 & 12 & 14 & 7 & 12 & 16 & 11 & 10 & 9 & 9 & 139 \\
\hline Melfa & 11 & 13 & 10 & 13 & 10 & 15 & 7 & 18 & 9 & 6 & 4 & 12 & 128 \\
\hline Edi & 9 & 10 & 18 & 10 & 12 & 15 & 14 & 10 & 8 & 3 & 7 & 5 & 121 \\
\hline Alfi & 14 & 15 & 14 & 13 & 14 & 14 & 11 & 12 & 17 & 6 & 10 & 12 & 152 \\
\hline Andi & 16 & 14 & 8 & 7 & 5 & 3 & 6 & 8 & 3 & 24 & 15 & 26 & 135 \\
\hline Totok & 12 & 12 & 14 & 6 & 5 & 3 & 6 & 6 & 5 & 21 & 16 & 20 & 126 \\
\hline Bapak & 1 & 4 & 0 & 2 & 0 & 0 & 2 & 0 & 0 & 6 & 3 & 3 & 21 \\
\hline Nova & 0 & 0 & 0 & 2 & 3 & 3 & 1 & 2 & 1 & 8 & 9 & 10 & 39 \\
\hline Imul & 0 & 0 & 0 & 0 & 0 & 3 & 3 & 0 & 1 & 7 & 3 & 4 & 21 \\
\hline Dedet & 0 & 0 & 0 & 0 & 0 & 0 & 0 & 0 & 0 & 10 & 10 & 8 & 28 \\
\hline Tomi & 0 & 0 & 0 & 0 & 0 & 0 & 0 & 0 & 0 & 0 & 6 & 7 & 13 \\
\hline \multicolumn{1}{c}{ Jumlah } & $\mathbf{8 5}$ & $\mathbf{9 6}$ & $\mathbf{8 7}$ & $\mathbf{7 8}$ & $\mathbf{7 3}$ & $\mathbf{7 3}$ & $\mathbf{7 0}$ & $\mathbf{8 7}$ & $\mathbf{7 2}$ & $\mathbf{1 0 9}$ & $\mathbf{1 0 3}$ & $\mathbf{1 2 8}$ & $\mathbf{1 0 6 1}$ \\
\hline
\end{tabular}

Tabel 2 Rekapitulasi Data Real Penjualan Mobil SAA Pekanbaru Tahun 2018

\begin{tabular}{|c|c|c|c|c|c|c|c|c|c|c|c|c|c|}
\hline \multirow{2}{*}{$\begin{array}{c}\text { Nama } \\
\text { Marketing }\end{array}$} & \multicolumn{12}{|c|}{ Jumlah Penjualan Setiap Bulan dalam Satuan unit } & \multirow{2}{*}{$\begin{array}{l}\text { Total } \\
\text { (unit) }\end{array}$} \\
\hline & 1 & 2 & 3 & 4 & 5 & 6 & 7 & 8 & 9 & 10 & 11 & 12 & \\
\hline Ali & 11 & 14 & 11 & 15 & 15 & 9 & 14 & 15 & 13 & 10 & 11 & 12 & 150 \\
\hline Remon & 7 & 13 & 11 & 7 & 15 & 11 & 13 & 6 & 13 & 21 & 17 & 15 & 149 \\
\hline Melfa & 9 & 12 & 13 & 15 & 15 & 6 & 8 & 12 & 9 & 18 & 7 & 13 & 137 \\
\hline Edi & 10 & 8 & 13 & 12 & 10 & 3 & 8 & 10 & 15 & 18 & 15 & 13 & 135 \\
\hline Alfi & 11 & 12 & 11 & 9 & 14 & 14 & 17 & 16 & 11 & 21 & 20 & 9 & 165 \\
\hline Andi & 25 & 17 & 22 & 15 & 22 & 9 & 20 & 5 & 3 & 2 & 0 & 0 & 140 \\
\hline Totok & 18 & 12 & 12 & 8 & 5 & 5 & 8 & 8 & 12 & 5 & 12 & 18 & 123 \\
\hline Bapak & 0 & 0 & 0 & 0 & 0 & 0 & 0 & 0 & 0 & 0 & 0 & 0 & 0 \\
\hline Nova & 5 & 4 & 8 & 10 & 6 & 7 & 9 & 9 & 10 & 7 & 11 & 9 & 95 \\
\hline Imul & 0 & 0 & 0 & 0 & 0 & 0 & 0 & 0 & 0 & 0 & 0 & 0 & 0 \\
\hline Dedet & 17 & 9 & 5 & 11 & 13 & 6 & 11 & 8 & 13 & 17 & 13 & 20 & 143 \\
\hline Tomi & 9 & 14 & 14 & 13 & 11 & 4 & 6 & 13 & 13 & 15 & 9 & 10 & 131 \\
\hline Hamdan & 0 & 0 & 3 & 1 & 0 & 0 & 0 & 0 & 1 & 0 & 0 & 1 & 6 \\
\hline Eka P & 0 & 0 & 0 & 0 & 0 & 0 & 0 & 0 & 0 & 0 & 6 & 3 & 9 \\
\hline Jumlah & 122 & 115 & 123 & 116 & 126 & 74 & 114 & 102 & 113 & 134 & 121 & 123 & 1383 \\
\hline
\end{tabular}

Metode Penelitian dilakukan bertujuan mendapatkan hasil yang tepat dalam meneyelesaikan masalah untuk menemukan jawaban terhadap objek yang diteliti. Agar penelitian berjalan sesuai dengan tujuan yang telah ditargetkan, terstruktur dan sistematis, maka penyusunan tahapan simulasi Monte Carlo perlu dilakukan yang ditunjukkan pada Gambar 1 
Sebagai tahap awal dari proses simulasi, dilakukan pengolahan dan transformasi data secara manual agar data yang digunakan dapat diterapkan. Penelitian ini melakukan Uji Coba pada tiga (3) orang Marketing yaitu Ali, Remon dan Melfa, dengan kode Maketing secara berurutan yaitu M001, M002 dan M003. Berikut langkah-langkah yang peneliti dilakukan.

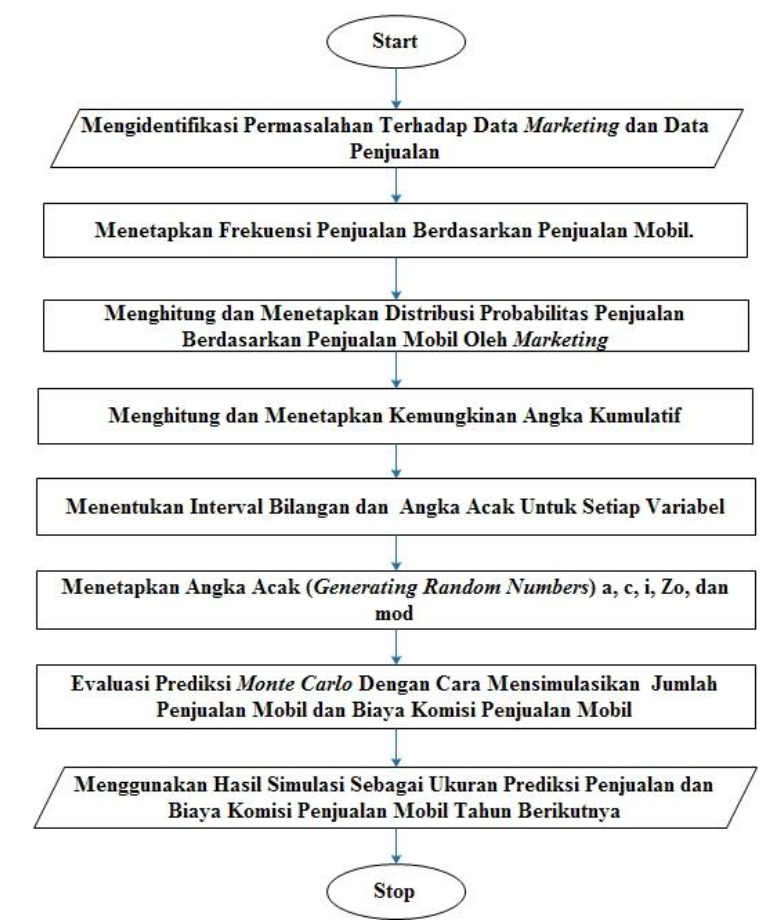

\section{Gambar 1 Flowchart Tahapan Metode Monte Carlo}

a. Mengidentifikasi Permasalahan Terhadap Data Marketing dan Data Penjualan.

Data yang diolah adalah atribut pada data real rekapitulasi penjualan mobil (Tabel 1 dan Tabel 2), kemudian diseleksi sesuai dengan kebutuhan sistem seperti Kode Marketing, Nama Marketing dan Komisi Marketing (Tabel 3), nilai komisi Marketing telah ditetapkan oleh SAA Pekanbaru sebesar Rp 1.000.000/unit, selanjutnya dikelompokkan untuk mendapatkan data percobaan simulasi yang ditunjukkan pada Tabel 4 dan Tabel 5.

Tabel 3 Daftar Marketing dan Biaya Komisi Penjualan

\begin{tabular}{ccc}
\hline Kode Marketing & $\begin{array}{c}\text { Nama } \\
\text { Marketing }\end{array}$ & Komisi \\
\hline M001 & Ali & $1,000,000 /$ unit \\
\hline M002 & Remon & $1,000,000 /$ unit \\
\hline M003 & Melfa & $1,000,000 /$ unit \\
\hline
\end{tabular}

Tabel 4 Data Percobaan Penjualan dan Komisi Penjualan Mobil Tahun 2017

\begin{tabular}{ccccccc}
\hline \multirow{2}{*}{ Bulan } & \multicolumn{2}{c}{ M001 } & \multicolumn{2}{c}{ M002 } & \multicolumn{2}{c}{ M003 } \\
\cline { 2 - 7 } & $\begin{array}{c}\text { Penjualan } \\
\text { (Unit) }\end{array}$ & $\begin{array}{c}\text { Komisi } \\
(\mathbf{R p})\end{array}$ & $\begin{array}{c}\text { Penjualan } \\
\text { (Unit) }\end{array}$ & $\begin{array}{c}\text { Komisi } \\
(\mathbf{R p})\end{array}$ & $\begin{array}{c}\text { Penjualan } \\
(\text { Unit })\end{array}$ & $\begin{array}{c}\text { Komisi } \\
(\mathbf{R p})\end{array}$ \\
\hline 1 & 8 & 8.000 .000 & 14 & 14.000 .000 & 11 & 11.000 .000 \\
\hline 2 & 15 & 15.000 .000 & 13 & 13.000 .000 & 13 & 13.000 .000 \\
\hline 3 & 11 & 11.000 .000 & 12 & 12.000 .000 & 10 & 10.000 .000 \\
\hline 4 & 13 & 13.000 .000 & 12 & 12.000 .000 & 13 & 13.000 .000 \\
\hline 5 & 10 & 10.000 .000 & 14 & 14.000 .000 & 10 & 10.000 .000 \\
\hline 6 & 10 & 10.000 .000 & 7 & 7.000 .000 & 15 & 15.000 .000 \\
\hline
\end{tabular}




\begin{tabular}{ccrcccr}
\hline 7 & 8 & 8.000 .000 & 12 & 12.000 .000 & 7 & 7.000 .000 \\
\hline 8 & 15 & 15.000 .000 & 16 & 16.000 .000 & 18 & 18.000 .000 \\
\hline 9 & 17 & 17.000 .000 & 11 & 11.000 .000 & 9 & 9.000 .000 \\
\hline 10 & 8 & 8.000 .000 & 10 & 10.000 .000 & 6 & 6.000 .000 \\
\hline 11 & 11 & 11.000 .000 & 9 & 9.000 .000 & 4 & 4.000 .000 \\
\hline 12 & 12 & 12.000 .000 & 9 & 9.000 .000 & 12 & 12.000 .000 \\
\hline Jumlah & $\mathbf{1 3 8}$ & $\mathbf{1 3 8 . 0 0 0 . 0 0 0}$ & $\mathbf{1 3 9}$ & $\mathbf{1 3 9 . 0 0 0 . 0 0 0}$ & $\mathbf{1 2 8}$ & $\mathbf{1 2 8 . 0 0 0 . 0 0 0}$ \\
\hline
\end{tabular}

Tabel 5 Data Percobaan Penjualan dan Komisi Penjualan Mobil Tahun 2018

\begin{tabular}{ccccccr}
\hline \multirow{2}{*}{ Bulan } & \multicolumn{2}{c}{ M001 } & \multicolumn{2}{c}{ M002 } & \multicolumn{2}{c}{ M003 } \\
\cline { 2 - 7 } & $\begin{array}{c}\text { Penjualan } \\
\text { (Unit) }\end{array}$ & $\begin{array}{c}\text { Komisi } \\
(\mathbf{R p})\end{array}$ & $\begin{array}{c}\text { Penjualan } \\
\text { (Unit) }\end{array}$ & $\begin{array}{c}\text { Komisi } \\
(\mathbf{R p})\end{array}$ & $\begin{array}{c}\text { Penjualan } \\
\text { (Unit) }\end{array}$ & $\begin{array}{c}\text { Komisi } \\
(\mathbf{R p})\end{array}$ \\
\hline 1 & 11 & 11.000 .000 & 7 & 7.000 .000 & 9 & 9.000 .000 \\
\hline 2 & 14 & 14.000 .000 & 13 & 13.000 .000 & 12 & 12.000 .000 \\
\hline 3 & 11 & 11.000 .000 & 11 & 11.000 .000 & 13 & 13.000 .000 \\
\hline 4 & 15 & 15.000 .000 & 7 & 7.000 .000 & 15 & 15.000 .000 \\
\hline 5 & 15 & 15.000 .000 & 15 & 15.000 .000 & 15 & 15.000 .000 \\
\hline 6 & 9 & 9.000 .000 & 11 & 11.000 .000 & 6 & 6.000 .000 \\
\hline 7 & 14 & 14.000 .000 & 13 & 13.000 .000 & 8 & 8.000 .000 \\
\hline 8 & 15 & 15.000 .000 & 6 & 6.000 .000 & 12 & 12.000 .000 \\
\hline 9 & 13 & 13.000 .000 & 13 & 13.000 .000 & 9 & 9.000 .000 \\
\hline 10 & 10 & 10.000 .000 & 21 & 21.000 .000 & 18 & 18.000 .000 \\
\hline 11 & 11 & 11.000 .000 & 17 & 17.000 .000 & 7 & 7.000 .000 \\
\hline 12 & 12 & 12.000 .000 & 15 & 15.000 .000 & 13 & 13.000 .000 \\
\hline Jumlah & $\mathbf{1 5 0}$ & $\mathbf{1 5 0 . 0 0 0 . 0 0 0}$ & $\mathbf{1 4 9}$ & $\mathbf{1 4 9 . 0 0 0 . 0 0 0}$ & $\mathbf{1 3 7}$ & $\mathbf{1 3 7 . 0 0 0 . 0 0 0}$ \\
\hline
\end{tabular}

b. Menetapkan Frekuensi Penjualan Berdasarkan Penjualan Mobil.

Frekuensi penjualan menunjukkan pola penjualan mobil, dengan menentukan angka serupa yang muncul menurut data pada Tabel 1, kemudian diakumulasikan dan menghasilkan kelompok data penjualan seperti ditunjukkan pada Tabel 6,Tabel 7 dan Tabel 8

Tabel 6 Penjualan M001

\begin{tabular}{cc}
\hline Penjualan M001 & Frekuensi Penjualan \\
\hline 8 & 3 \\
\hline 10 & 2 \\
\hline 11 & 2 \\
\hline 12 & 1 \\
\hline 13 & 1 \\
\hline 15 & 2 \\
\hline 17 & 1 \\
\hline Total & 12 Bulan \\
\hline
\end{tabular}

Tabel 7 Penjualan M002

\begin{tabular}{cc}
\hline Penjualan M002 & Frekuensi Penjualan \\
\hline 7 & 1 \\
\hline 9 & 2 \\
\hline 10 & 1 \\
\hline 11 & 1 \\
\hline 12 & 3 \\
\hline 13 & 1 \\
\hline 14 & 2 \\
\hline 16 & 1 \\
\hline Total & 12 Bulan
\end{tabular}


Tabel 8 Penjualan M003

\begin{tabular}{cc}
\hline Penjualan M003 & Frekuensi Penjualan \\
\hline 4 & 1 \\
\hline 6 & 1 \\
\hline 7 & 1 \\
\hline 9 & 1 \\
\hline 10 & 2 \\
\hline 11 & 1 \\
\hline 12 & 1 \\
\hline 13 & 2 \\
\hline 15 & 1 \\
\hline 18 & 1 \\
\hline Total & 12 Bulan \\
\hline
\end{tabular}

c. Menghitung dan Menetapkan Distribusi Probabilitas Penjualan Berdasarkan Penjualan Mobil

Oleh Marketing.

Menghitung distribusi probabilitas penjualan mobil terhadap kode Marketing M001, M002, dan M003 menggunakan rumus :

$$
\mathrm{P}_{\mathrm{i}}=f i / \mathrm{n}
$$

Keterangan :

$P_{i}$ : Probabilitas penjualan i

fi : Frekuensi penjualan i

$n$ : Total frekuensi penjualan.

jika perhitungan probabilitasnya benar maka total nilai yang dihasilkan bernilai 1. Perhitungan distribusi probabilitas selanjutnya ditunjukkan pada Tabel 9, Tabel 10 dan Tabel 11.

Tabel 9 Distribusi Probabilitas Penjualan M001

\begin{tabular}{cc}
\hline Penjualan M001 & Distribusi probabilitas penjualan \\
\hline 8 & $3 / 12=0,25$ \\
\hline 10 & $2 / 12=0,17$ \\
\hline 11 & $2 / 12=0,17$ \\
\hline 12 & $1 / 12=0,08$ \\
\hline 13 & $1 / 12=0,08$ \\
\hline 15 & $2 / 12=0,17$ \\
\hline 17 & $1 / 12=0,08$ \\
\hline Total & $12 / 12=1$ \\
\hline
\end{tabular}

Tabel 10 Distribusi Probabilitas Penjualan M002

\begin{tabular}{cc}
\hline Penjualan M002 & Distribusi probabilitas penjualan \\
\hline 7 & $1 / 12=0,08$ \\
\hline 9 & $2 / 12=0,17$ \\
\hline 10 & $1 / 12=0,08$ \\
\hline 11 & $1 / 12=0,08$ \\
\hline 12 & $3 / 12=0,25$ \\
\hline 13 & $1 / 12=0,08$ \\
\hline 14 & $2 / 12=0,17$ \\
\hline 16 & $1 / 12=0,08$ \\
\hline Total & $12 / 12=1$ \\
\hline
\end{tabular}

Tabel 11 Distribusi Probabilitas Penjualan M003

\begin{tabular}{cc}
\hline Penjualan M003 & Distribusi probabilitas penjualan \\
\hline 4 & $1 / 12=0,08$ \\
\hline 6 & $1 / 12=0,08$ \\
\hline 7 & $1 / 12=0,08$ \\
\hline
\end{tabular}




\begin{tabular}{cc}
\hline 9 & $1 / 12=0,08$ \\
\hline 10 & $2 / 12=0,17$ \\
\hline 11 & $1 / 12=0,08$ \\
\hline 12 & $1 / 12=0,08$ \\
\hline 13 & $2 / 12=0,17$ \\
\hline 15 & $1 / 12=0,08$ \\
\hline 18 & $1 / 12=0,08$ \\
\hline Total & $12 / 12=1$ \\
\hline
\end{tabular}

d. Menghitung dan Menetapkan Kemungkinan Angka Kumulatif

Perhitungan kemungkinan angka kumulatif berdasarkan distribusi probabilitas penjualan, dilakukan dengan cara menjumlahkan setiap angka probabilitas penjualan ditambahkan dengan angka kemungkinan kumulatif sebelumnya hingga mendapatkan total ke-n nya bernilai 1 .

Perhitungan kemungkinan angka kumulatif ditunjukkan pada Tabel 12, Tabel 13dan Tabel 14.

Tabel 12 Kemungkinan Kumulatif Penjualan M001

\begin{tabular}{ccc}
\hline Penjualan M001 & Distribusi probabilitas penjualan & Kemungkinan Kumulatif \\
\hline 8 & $3 / 12=0,25$ & 0,25 \\
\hline 10 & $2 / 12=0,17$ & 0,42 \\
\hline 11 & $2 / 12=0,17$ & 0,58 \\
\hline 12 & $1 / 12=0,08$ & 0,67 \\
\hline 13 & $1 / 12=0,08$ & 0,75 \\
\hline 15 & $2 / 12=0,17$ & 0,92 \\
\hline 17 & $1 / 12=0,08$ & 1 \\
\hline
\end{tabular}

Tabel 13 Kemungkinan Kumulatif Penjualan M002

\begin{tabular}{ccc}
\hline Penjualan M002 & Distribusi probabilitas penjualan & Kemungkinan Kumulatif \\
\hline 7 & $1 / 12=0,08$ & 0,08 \\
\hline 9 & $2 / 12=0,17$ & 0,25 \\
\hline 10 & $1 / 12=0,08$ & 0,33 \\
\hline 11 & $1 / 12=0,08$ & 0,42 \\
\hline 12 & $3 / 12=0,25$ & 0,67 \\
\hline 13 & $1 / 12=0,08$ & 0,75 \\
\hline 16 & $2 / 12=0,17$ & 0,92 \\
\hline
\end{tabular}

Tabel 14 Kemungkinan Kumulatif Penjualan M003

\begin{tabular}{ccc}
\hline Penjualan M003 & Distribusi probabilitas penjualan & Kemungkinan Kumulatif \\
\hline 4 & $1 / 12=0,08$ & 0,08 \\
\hline 6 & $1 / 12=0,08$ & 0,17 \\
\hline 7 & $1 / 12=0,08$ & 0,25 \\
\hline 9 & $1 / 12=0,08$ & 0,33 \\
\hline 10 & $2 / 12=0,17$ & 0,50 \\
\hline 11 & $1 / 12=0,08$ & 0,58 \\
\hline 12 & $1 / 12=0,08$ & 0,67 \\
\hline 13 & $2 / 12=0,17$ & 0,83 \\
\hline 18 & $1 / 12=0,08$ & 0,92 \\
\hline
\end{tabular}

e. Menentukan Interval Bilangan dan Angka Acak Untuk Setiap Variabel.

Perhitungan interval bilangan berdasarkan hasil kemungkinan kumulatif, Sedangkan bilangan acak yang digunakan adalah bilangan acak 2 digit sehingga nilai distribusi probabilitas penjualan dan probabilitas kumulatif memiliki 2 digit belakang koma. Adapun interval angka 
acak M001, M002 dan M003 didapat dari proses perhitungan algoritma Monte Carlo distribusi probabilitas dan distribusi kumulatif yaitu M001, ke-i=00 sampai dengan probabilitas kumulatif ke-i dikurang 1. Setelah itu hasil ke-i dikurang 1 dijadikan untuk perhitungan berikutnya hingga didapat angka 99. Perhitungan interval bilangan dan angka acak selanjutnya ditunjukkan pada Tabel 15, Tabel 16, dan Tabel 17.

Tabel 15 Interval Angka Acak Penjualan M001

\begin{tabular}{cccc}
\hline $\begin{array}{c}\text { Penjualan } \\
\text { M001 }\end{array}$ & Distribusi Probabilitas Penjualan & $\begin{array}{c}\text { Kemungkinan } \\
\text { Kumulatif }\end{array}$ & $\begin{array}{c}\text { Interval Angka } \\
\text { Acak }\end{array}$ \\
\hline 8 & $3 / 12=0,25$ & 0,25 & $00 \mathrm{~s} / \mathrm{d} 24$ \\
\hline 10 & $2 / 12=0,17$ & 0,42 & $25 \mathrm{~s} / \mathrm{d} 41$ \\
\hline 11 & $2 / 12=0,17$ & 0,58 & $42 \mathrm{~s} / \mathrm{d} 57$ \\
\hline 12 & $1 / 12=0,08$ & 0,67 & $58 \mathrm{~s} / \mathrm{d} 66$ \\
\hline 13 & $1 / 12=0,08$ & 0,75 & $67 \mathrm{~s} / \mathrm{d} 74$ \\
\hline 15 & $2 / 12=0,17$ & 0,92 & $75 \mathrm{~s} / \mathrm{d} 91$ \\
\hline 17 & $1 / 12=0,08$ & 1 & $92 \mathrm{~s} / \mathrm{d} 99$ \\
\hline
\end{tabular}

Tabel 16 Interval Angka Acak Penjualan M002

\begin{tabular}{cccc}
\hline $\begin{array}{c}\text { Penjualan } \\
\text { M002 }\end{array}$ & Distribusi Probabilitas Penjualan & $\begin{array}{c}\text { Kemungkinan } \\
\text { Kumulatif }\end{array}$ & $\begin{array}{c}\text { Interval Angka } \\
\text { Acak }\end{array}$ \\
\hline 7 & $1 / 12=0,08$ & 0,08 & $00 \mathrm{~s} / \mathrm{d} 07$ \\
\hline 9 & $2 / 12=0,17$ & 0,25 & $08 \mathrm{~s} / \mathrm{d} 24$ \\
\hline 10 & $1 / 12=0,08$ & 0,33 & $25 \mathrm{~s} / \mathrm{d} 32$ \\
\hline 11 & $1 / 12=0,08$ & 0,42 & $33 \mathrm{~s} / \mathrm{d} 41$ \\
\hline 12 & $3 / 12=0,25$ & 0,67 & $42 \mathrm{~s} / \mathrm{d} 66$ \\
\hline 13 & $1 / 12=0,08$ & 0,75 & $67 \mathrm{~s} / \mathrm{d} 74$ \\
\hline 14 & $2 / 12=0,17$ & 0,92 & $75 \mathrm{~s} / \mathrm{d} 91$ \\
\hline 16 & $1 / 12=0,08$ & 1 & $92 \mathrm{~s} / \mathrm{d} 99$ \\
\hline
\end{tabular}

Tabel 17 Interval Angka Acak Penjualan M003

\begin{tabular}{cccc}
\hline $\begin{array}{c}\text { Penjualan } \\
\text { M003 }\end{array}$ & Distribusi Probabilitas Penjualan & $\begin{array}{c}\text { Kemungkinan } \\
\text { Kumulatif }\end{array}$ & $\begin{array}{c}\text { Interval Angka } \\
\text { Acak }\end{array}$ \\
\hline 4 & $1 / 12=0,08$ & 0,08 & $00 \mathrm{~s} / \mathrm{d} 07$ \\
\hline 6 & $1 / 12=0,08$ & 0,17 & $08 \mathrm{~s} / \mathrm{d} 16$ \\
\hline 7 & $1 / 12=0,08$ & 0,25 & $17 \mathrm{~s} / \mathrm{d} 24$ \\
\hline 9 & $1 / 12=0,08$ & 0,33 & $25 \mathrm{~s} / \mathrm{d} 32$ \\
\hline 10 & $2 / 12=0,17$ & 0,50 & $33 \mathrm{~s} / \mathrm{d} 49$ \\
\hline 11 & $1 / 12=0,08$ & 0,58 & $50 \mathrm{~s} / \mathrm{d} 57$ \\
\hline 12 & $1 / 12=0,08$ & 0,67 & $58 \mathrm{~s} / \mathrm{d} 66$ \\
\hline 13 & $2 / 12=0,17$ & 0,83 & $67 \mathrm{~s} / \mathrm{d} 82$ \\
\hline 15 & $1 / 12=0,08$ & 0,92 & $83 \mathrm{~s} / \mathrm{d} 91$ \\
\hline 18 & $1 / 12=0,08$ & 1 & $92 \mathrm{~s} / \mathrm{d} 99$ \\
\hline
\end{tabular}

f. Menetapkan Angka Acak (Generating Random Numbers) a, c, i, Zo, dan mod.

Menetapkan atau membentuk angka acak dapat dilakukan dengan rumus dan ketentuan sebagai berikut:

$$
\text { Rumus }: Z i+1=(a . Z i+c) \bmod .
$$

Diketahui : $\mathrm{a}=2, \mathrm{c}=25, \mathrm{~m}=99$, dan $\mathrm{Zo}=22$

Pengurutan rangkaian perhitungan angka acak dari tahap pertama sampai pada tahap terakhir akan menghasilkan nilai seperti terdapat pada Tabel 18. 
Tabel 18 Bentuk Generating Random Numbers

\begin{tabular}{|c|c|c|c|}
\hline$I$ & $(a . Z i+c)$ & $Z i+1=(a . Z i+c) \bmod m$ & Angka Acak \\
\hline 1 & 22 & 69 & 69 \\
\hline 2 & 69 & 163 & 64 \\
\hline 3 & 64 & 153 & 54 \\
\hline 4 & 54 & 133 & 34 \\
\hline 5 & 34 & 93 & 93 \\
\hline 6 & 93 & 211 & 13 \\
\hline 7 & 13 & 51 & 51 \\
\hline 8 & 51 & 127 & 28 \\
\hline 9 & 28 & 81 & 81 \\
\hline 10 & 81 & 187 & 88 \\
\hline 11 & 88 & 201 & 3 \\
\hline 12 & 3 & 31 & 31 \\
\hline
\end{tabular}

g. Evaluasi Prediksi Monte Carlo Dengan Cara Mensimulasikan Jumlah Penjualan Mobil dan Biaya Komisi Penjualan Mobil.

Pada tahap ini adalah membuat simulasi dari sebuah eksprimen dan beberapa percobaan telah diproses sebelumya dengan mengambil angka acak yang telah ditentukan (Generating Random Numbers) pada Tabel 18. Selanjutnya dari beberapa eksperiment tersebut menunjukkan simulasi jumlah penjualan mobil oleh Marketing di SAA Pekanbaru periode tahun berikutnya, yakni dari bulan Januari 2018 hingga Desember 2018 dan biaya komisi penjualan mobil, sehingga hasil simulasi dari serangkaian percobaan yang telah dilalui tersebut dapat dilihat pada Tabel 19.

Tabel 19 Simulasi Penjualan Mobil Tahun 2018

\begin{tabular}{|c|c|c|c|c|c|c|c|}
\hline \multirow[b]{2}{*}{ Bulan } & \multirow{2}{*}{$\begin{array}{c}\text { Angka } \\
\text { Acak }\end{array}$} & \multicolumn{2}{|c|}{ M001 } & \multicolumn{2}{|c|}{ M002 } & \multicolumn{2}{|c|}{ M003 } \\
\hline & & $\begin{array}{c}\text { Penjualan } \\
\text { (Unit) }\end{array}$ & $\begin{array}{c}\text { Komisi } \\
(\mathbf{R p})\end{array}$ & $\begin{array}{c}\text { Penjualan } \\
\text { (Unit) }\end{array}$ & $\begin{array}{c}\text { Komisi } \\
\text { (Rp) }\end{array}$ & $\begin{array}{c}\text { Penjualan } \\
\text { (Unit) }\end{array}$ & $\begin{array}{c}\text { Komisi } \\
\text { (Rp) }\end{array}$ \\
\hline 1 & 69 & 13 & 13.000 .000 & 13 & 13.000 .000 & 13 & 13.000 .000 \\
\hline 2 & 64 & 12 & 12.000 .000 & 12 & 12.000 .000 & 12 & 12.000 .000 \\
\hline 3 & 54 & 11 & 11.000 .000 & 12 & 12.000 .000 & 11 & 11.000 .000 \\
\hline 4 & 34 & 10 & 10.000 .000 & 11 & 11.000 .000 & 10 & 10.000 .000 \\
\hline 5 & 93 & 17 & 17.000 .000 & 16 & 16.000 .000 & 18 & 18.000 .000 \\
\hline 6 & 13 & 8 & 8.000 .000 & 9 & 9.000 .000 & 6 & 6.000 .000 \\
\hline 7 & 51 & 11 & 11.000 .000 & 12 & 12.000 .000 & 11 & 11.000 .000 \\
\hline 8 & 28 & 10 & 10.000 .000 & 10 & 10.000 .000 & 9 & 9.000 .000 \\
\hline 9 & 81 & 15 & 15.000 .000 & 14 & 14.000 .000 & 13 & 13.000 .000 \\
\hline 10 & 88 & 15 & 15.000 .000 & 14 & 14.000 .000 & 15 & 15.000 .000 \\
\hline 11 & 3 & 8 & 8.000 .000 & 7 & 7.000 .000 & 4 & 4.000 .000 \\
\hline 12 & 31 & 10 & 10.000 .000 & 10 & 10.000 .000 & 9 & 9.000 .000 \\
\hline \multicolumn{2}{|c|}{ Jumlah } & 140 & 140.000 .000 & 140 & 140.000 .000 & 131 & 131.000 .000 \\
\hline
\end{tabular}

h. Menggunakan Hasil Simulasi Sebagai Ukuran Prediksi Penjualan dan Biaya Komisi Penjualan Mobil Tahun Berikutnya.

Setelah melakukan 3 percobaan dari serangkaian metode Monte Carlo untuk biaya komisi penjualan mobil di SAA Pekanbaru maka dapat dihasilkan beberapa perbedaan prediksi tergantung dari angka acak yang akan digunakan untuk melakukan perhitungan, dari hasil yang telah didapatkan jumlah yang tidak terlalu berbeda jauh dari data real penjualan mobil pada tahun 2018, artinya data penjualan mobil tahun 2017 yang diolah merupakan pola pengulangan untuk menciptakan sebuah prediksi agar mengikuti angka-angka sebelumnya, bisa berkurang atau bertambah tergantung angka acak yang digunakan pada proses generating random numbers. 


\section{Hasil dan Diskusi}

Pada tahap ini dilakukan perbandingan antara hasil simulasi penjualan mobil dan komisi penjualan mobil Tahun 2018 (Tabel 19) dengan data real penjulan mobil dan komisi penjualan mobil Tahun 2018 (Tabel 20), Kemudian hasil perbandingan tersebut menjadi penilaian akurasi yang ditunjukkan pada Tabel 21.

Tabel 20 Data Real Penjualan Mobil Dan Komisi Penjualan Mobil Tahun 2018

\begin{tabular}{ccccccr}
\hline \multirow{2}{*}{ Bulan } & \multicolumn{2}{c}{ M001 } & \multicolumn{2}{c}{ M002 } & \multicolumn{2}{c}{ M003 } \\
\cline { 2 - 8 } & $\begin{array}{c}\text { Penjualan } \\
\text { (Unit) }\end{array}$ & $\begin{array}{c}\text { Komisi } \\
(\mathbf{R p})\end{array}$ & $\begin{array}{c}\text { Penjualan } \\
\text { (Unit) }\end{array}$ & $\begin{array}{c}\text { Komisi } \\
(\mathbf{R p})\end{array}$ & $\begin{array}{c}\text { Penjualan } \\
\text { (Unit) }\end{array}$ & $\begin{array}{c}\text { Komisi } \\
(\mathbf{R p})\end{array}$ \\
\hline 1 & 11 & 11.000 .000 & 7 & 7.000 .000 & 9 & 9.000 .000 \\
\hline 2 & 14 & 14.000 .000 & 13 & 13.000 .000 & 12 & 12.000 .000 \\
\hline 3 & 11 & 11.000 .000 & 11 & 11.000 .000 & 13 & 13.000 .000 \\
\hline 4 & 15 & 15.000 .000 & 7 & 7.000 .000 & 15 & 15.000 .000 \\
\hline 5 & 15 & 15.000 .000 & 15 & 15.000 .000 & 15 & 15.000 .000 \\
\hline 6 & 9 & 9.000 .000 & 11 & 11.000 .000 & 6 & 6.000 .000 \\
\hline 7 & 14 & 14.000 .000 & 13 & 13.000 .000 & 8 & 8.000 .000 \\
\hline 8 & 15 & 15.000 .000 & 6 & 6.000 .000 & 12 & 12.000 .000 \\
\hline 9 & 13 & 13.000 .000 & 13 & 13.000 .000 & 9 & 9.000 .000 \\
\hline 10 & 10 & 10.000 .000 & 21 & 21.000 .000 & 18 & 18.000 .000 \\
\hline 11 & 11 & 11.000 .000 & 17 & 17.000 .000 & 7 & 7.000 .000 \\
\hline 12 & 12 & 12.000 .000 & 15 & 15.000 .000 & 13 & 13.000 .000 \\
\hline Jumlah & $\mathbf{1 5 0}$ & $\mathbf{1 5 0 . 0 0 0 . 0 0 0}$ & $\mathbf{1 4 9}$ & $\mathbf{1 4 9 . 0 0 0 . 0 0 0}$ & $\mathbf{1 3 7}$ & $\mathbf{1 3 7 . 0 0 0 . 0 0 0}$ \\
\hline
\end{tabular}

Tabel 21 Akurasi Simulasi Penjualan Mobil Dan Komisi Penjualan Mobil Terhadap Data Real

\begin{tabular}{|c|c|c|c|c|c|c|}
\hline $\begin{array}{c}\text { Kode } \\
\text { Marke } \\
\text { ting }\end{array}$ & $\begin{array}{c}\text { Nama } \\
\text { Marke } \\
\text { ting }\end{array}$ & $\begin{array}{c}\text { Hasil } \\
\text { Simulasi } \\
\text { Penjualan } \\
\text { Tahun 2018 } \\
\text { (Unit) } \\
\end{array}$ & $\begin{array}{c}\text { Data Real } \\
\text { Penjualan } \\
\text { Tahun } \\
2018 \\
\text { (Unit) } \\
\end{array}$ & $\begin{array}{c}\text { Hasil Simulasi } \\
\text { Komisi } \\
\text { Penjualan } \\
\text { Tahun 2018 } \\
\text { (Rp) } \\
\end{array}$ & $\begin{array}{c}\text { Data Real } \\
\text { Komisi } \\
\text { Penjualan } \\
\text { Tahun } 2018 \\
\text { (Rp) }\end{array}$ & $\begin{array}{c}\text { Akurasi } \\
(\%)\end{array}$ \\
\hline M001 & Ali & 140 & 150 & 140.000 .000 & 150.000 .000 & $93 \%$ \\
\hline M002 & Remon & 140 & 149 & 140.000 .000 & 149.000 .000 & $94 \%$ \\
\hline M003 & Melfa & 131 & 137 & 131.000 .000 & 137.000 .000 & $96 \%$ \\
\hline \multicolumn{2}{|c|}{ Total } & 411 & 436 & 411.000.000 & 436.000.000 & $94 \%$ \\
\hline
\end{tabular}

Pada Tabel 21 menjelaskan bahwa untuk Tahun 2018 hasil simulasi menunjukkan penjualan mobil berjumlah 411 unit dan biaya komisi penjualan mobil sebesar Rp 411.000 .000 dan jika dibandingkan dengan data real Tahun 2018 untuk penjualan mobil sebanyak 436 unit dan biaya komisi penjualan sebesar Rp 436.000.000 diperoleh rata-rata akurasi prediksi sebesar $94 \%$.

\section{Kesimpulan}

Dari hasil uji coba prediksi biaya komisi penjualan mobil menggunakan metode Monte Carlo memperoleh akurasi prediksi yang cukup tinggi yakni sebesar 94\%. Dengan demikian perhitungan peramalan biaya komisi penjualan mobil dianggap layak dan dapat direkomendasikan, sehingga mampu untuk menyelesaikan masalah prediksi biaya komisi penjualan mobil dimasa akan datang.

\section{Referensi}

[1] Untari, S. N., Djaja, S., \& Widodo, J. (2018). Strategi Pemasaran Mobil Merek Daihatsu Pada Dealer Daihatsu Jember. Jurnal Pendidikan Ekonomi: Jurnal Ilmiah Ilmu Pendidikan, Ilmu Ekonomi dan Ilmu Sosial, 11(2), 82-88.. DOI:https://doi.org/10.19184/jpe.v11i2.6451 
[2] Simamora, R. J. (2018). Simulasi Monte Carlo Dengan Model Persediaan Stokastik Pada Pt. Bingei Medan. Jurnal Teknik Informatika Kaputama, 1(2), 30-35.

DOI : https://doi.org/10.31227/osf.io/vjpn5

[3] Devara, K. S., \& Sulistyawati, E. Peran Inovasi Produk Dalam Memediasi Pengaruh Orientasi Pasar Terhadap Kinerja Pemasaran. E-Jurnal Manajemen,8(10),6367-6387

DOI:https://doi.org/10.24843/EJMUNUD.2019.v08.i10.p25

[4] Darma, P. S. B., \& Wirawati, N. G. P. Pengaruh Pendapatan Kamar dan Biaya Komisi Penjualan Terhadap Average Room Rate Hotel di Daerah Denpasar. E-Jurnal Akuntansi, 21292153.DOI:https://doi.org/10.24843/EJA.2019.v27.i03.p18

[5] Aprillia, F., \& Pratama, R. (2019). Aplikasi Insentif Berbasis Web Pada PT. St Morita Industries. Ensiklopedia of Journal, 1(2). DOI : https://doi.org/10.33559/eoj.v1i2.35

[6] Yusmaity., Santony, J. dan Yuhandri. (2019). Simulasi Monte Carlo untuk Memprediksi Hasil Ujian Nasional (Studi Kasus di SMKN 2 Pekanbaru), Jurnal Informasi \& Teknologi. 1. 1-6. DOI: https://doi.org/10.35134/jidt.v1i4.11

[7] Syahrin, E., Santony, J., \& Na'am, J. (2018). Pemodelan Penjualan Produk Herbal Menggunakan Metode Monte Carlo. Jurnal KomtekInfo, 5(3), 33-41.

DOI :https://doi.org/10.29165/komtekinfo.v5i2

[8] Nurdini, S., Nurcahyo, G. W., \& Santony, J. (2019). Analisis Perkiraan Jumlah Produksi Tahu Menggunakan Metode Fuzzy Sugeno. Jurnal Sistim Informasi dan Teknologi, 1(3), 19-24. DOI :

[9] Sucipto, S., Indriati, R., \& Hariawaan, F. B. (2017). Desain Database Untuk Optimalisasi Sistem Prediksi Transaksi Penjualan. JIPI (Jurnal Ilmiah Penelitian dan Pembelajaran Informatika), 2(2). DOI : http://dx.doi.org/10.29100/jipi.v2i2.367

[10] Profita, A. (2017). Optimasi Manajemen Persediaan Darah Menggunakan Simulasi Monte Carlo. Journal of Industrial Engineering Management, 2(1), 16-24.

DOI : https://doi.org/10.33536/jiem.v2i1.101

[11] Senitio, G. B., Santony, J., \& Na'am, J. (2018). Tingkat Prediksi Pendaftar Ujian Kompetensi Laboratorium Menggunakan Metode Least Square. Jurnal RESTI (Rekayasa Sistem dan Teknologi Informasi), 2(3), 746-752. DOI: https://doi.org/10.29207/resti.v2i3.530

[12] Geni, B. Y., \& Santony, J. (2019). Prediksi Pendapatan Terbesar pada Penjualan Produk Cat dengan Menggunakan Metode Monte Carlo. Jurnal Informatika Ekonomi Bisnis, 1(4), 15-20. DOI : https://doi.org/10.37034/infeb.v1i4.5

[13] Zulfiandry, R. (2018). Optimasi Kegiatan Pelatihan Menggunakan Metode Simulasi Monte Carlo (Studi Kasus di Balai Latihan Kerja Dinas Tenaga Kerja dan Transmigrasi Provinsi Bengkulu). ILKOM Jurnal Ilmiah, 10(1), 113-119.DOI:http://dx.doi.org/10.33096/ilkom.v10i1.252.113-119

[14] Manurung, K. H., \& Santony, J. (2019). Simulasi Pengadaan Barang menggunakan Metode Monte Carlo. Jurnal Sistim Informasi dan Teknologi, 1(3), 7-11.

DOI : https://doi.org/10.35134/jsisfotek.v1i3.3

[15] Muflihunallah, M., Dharmawan, K., \& Asih, N. M. (2018). Estimasi Nilai Implied Volatility Menggunakan Simulasi Monte Carlo. E-Jurnal Matematika, 7(3), 239-245. DOI:https://doi.org/10.24843/MTK.2018.v07.i03.p209

[16] Astia, R. Y., Santony, J., \& Sumijan, S. (2019). Prediction Of Amount Of Use Of Planning Family Contraception Equipment Using Monte Carlo Method (Case Study In Linggo Sari Baganti District). Indonesian Journal of Artificial Intelligence and Data Mining, 2(1), 28-36. DOI:http://dx.doi.org/10.24014/ijaidm.v2i1.5825

[17] Hartini, E., Adrial, H., \& Pujiarta, S. (2019). Reliability Analysis Of Primary And Purification Pumps In Rsg-Gas Using Monte Carlo Simulation Approach. Jurnal Teknologi Reaktor Nuklir Tri Dasa Mega, 21(1), 15-22. DOI: http://dx.doi.org/10.17146/tdm.2019.21.1.5311

[18] Adisalam, B. G., Gunawan, P. H., \& Imrona, M. (2017). Deteksi Kemacetan Lalu Lintas dengan Menggunakan Algoritma Monte Carlo. Indonesia Journal on Computing (Indo-JC), 2(2), 23-36. DOI:http://dx.doi.org/10.21108/INDOJC.2017.2.2.174

[19] Iriawan, N. U. R., Fithriasari, K., Ulama, B. S. S., Suryaningtyas, W., Susanto, I., \& Pravitasari, A. A. (2018). Bayesian Bernoulli mixture regression model for Bidikmisi scholarship classification. Jurnal Ilmu Komputer dan Informasi, 11(2), 67-76. DOI : http://dx.doi.org/10.21609/jiki.v11i2.536 
Zupri Henra Hartomi ${ }^{1}$, Yuhandri ${ }^{2}$, Julius Santony ${ }^{3}$

[20] Woo, H., Chung, W., Graham, J. M., \& Lee, B. (2017). Forest fire risk assessment using point process modelling of fire occurrence and Monte Carlo fire simulation. International journal of wildland fire, 26(9), 789-805. DOI : https://doi.org/10.1071/WF17021 